\title{
La narrativa conversacional como mecanismo de liderazgo y cohesión social
}

Fecha de recepción: 27 de septiembre de 2011 - Aceptación: 15 de noviembre de 2011

\section{Mireya Cisneros Estupiñán - Gladys Yolanda Pasuy Guerrero}

\section{Resumen}

El presente artículo constituye una aproximación al componente evaluativo de las narrativas conversacionales en un grupo de personas adictas a sustancias psicoactivas que acuden al centro de rehabilitación Casa Renacer. En el análisis, se examina las historias narradas para demostrar cómo éstas revelan el imaginario que los internos tienen acerca de su condición. Nuestro análisis muestra que las narrativas conversacionales que se realizan en este espacio no cumplen principalmente con una función terapéutica, sino más bien de liderazgo y cohesión social.

El marco de referencia en el cual se encuadran estas líneas, se basa en la obra de William Labov La transformación de la experiencia en sintaxis narrativa. El corpus a analizar corresponde al trabajo de campo, fruto de las visitas a la "Casa Renacer" y de las grabaciones obtenidas durante dichos encuentros.

\section{Abstract}

The following article makes up an approach to the conversational narratives evaluative component of a group of people addicted to psychoactive substances that come to the rehabilitation centre Casa Renacer. In the analysis, the narrated stories are studied for proving how theses reveal the imaginary that the interns have about their condition. Our analysis shows that the conversational narratives made in this environment do not carry out mainly with a therapeutic function but with a leadership and social cohesive purpose.

The framework in which these lines are framed is based on the work of William Labov The transformation of experience in narrative syntax. The corpus to be analyzed corresponds to field work, as a result of the visits to "Casa Renacer" and the recordings got during these meetings.

\section{Palabras clave}

Cohesión social, liderazgo, discurso reproducido, narrativa conversacional, sintaxis narrativa, evaluación, comunidad de habla.

\section{Keywords}

Leadership and social cohesion, speech reproduced, conversational narrative, narrative syntax, evaluation, speech community.

\section{Introducción}

Es bien conocido que un sector importante de las investigaciones lingüísticas contemporáneas se propone estudiar la lengua en uso y la explicación de las funciones de esas formas lingüísticas en contexto, en otra palabras, no es suficiente con la descripción de las estructuras lingüísticas, sino que éstas deben interpretarse en el espacio y las circunstancias en las que fueron producidas. Desde tal tendencia, este análisis se hace a partir de intercambios conver- 
sacionales cara a cara, con participantes reales, quienes explican la forma como proceden para lograr sus metas de interacción comunicativa. En esa medida, recogemos la experiencia de la visita a la comunidad de habla de las personas internas en un centro de rehabilitación de drogadictos, denominado Casa Renacer.

\section{Reseña de autores \\ Mireya Cisneros Estupiñán (Colombia) \\ Profesora de la Universidad Tecnológica de Pereira mireyace@yahoo.com}

Doctora en Ciencias de la Educación, Universidad del Cauca. Magíster en Lingüística Española, Instituto Caro y Cuervo. Licenciada en Filosofía y Letras, Universidad de Nariño. Especializada como profesora e investigadora, ICl-AECl, Madrid. Profesora de la Universidad Tecnológica de Pereira desde 2003. Directora del Departamento de Lingüística del Instituto Caro y Cuervo, 1995-2002. Directora del Grupo “Estudios del lenguaje y la educación", Categoría A de Colciencias. Miembro de la Junta Directiva de la Asociación Internacional de Lingüística ALFAL y del Grupo EDICE de la Universidad de Estocolmo (Suecia). Par evaluadora de Colciencias y del Ministerio de Educación Nacional. Miembro de comités científicos de revistas especializadas en el ámbito nacional e internacional. Autora de libros y artículos en revistas especializadas. Ponente en eventos nacionales e internacionales.

\section{Gladys Yolanda Pasuy Guerrero (Colombia) Profesora de la Universidad de Caldas vikypasuy@yahoo.com}

Magíster en Lingüística Española, Instituto Caro y Cuervo. Licenciada en Filología e Idiomas de la Universidad INCCA de Colombia. Profesora del área de Lingüística y de Español como segunda lengua en la Facultad de Artes y Humanidades, Universidad de Caldas. Profesora de la Maestría en Lingüística de la Universidad Tecnológica de Pereira. Miembro de la Asociación Internacional de Lingüística ALFAL y de la Red de enseñanza del español como lengua extranjera, EnRedEle. Representante de la Universidad de Caldas en ASCUN y en el Sistema internacional de certificación del español como lengua extranjera, SICELE. Ha participado en eventos nacionales e internacionales relacionados con la Lingüística. Sus áreas de investigación son: Sociolingüística, Análisis del discurso, Métodos y técnicas de enseñanza, en el grupo "Lenguas y discursos" de la Universidad de Caldas.
Este centro fue fundado por una comunidad cristiana, que promulga el tratamiento y la reinserción social mediante la oración cristiana. Está situado en el centro de la ciudad de Bogotá y recibe personas adictas a sustancias psicoactivas; allí, en un edificio de tres pisos, ocho alcobas, una cocineta, una terraza y un baño, se alberga precariamente a un promedio de cuarenta internos que, voluntariamente, acuden a "La Casa", supuestamente, para cubrir sus necesidades básicas, al tiempo que buscan rehabilitarse y reinsertarse en la instituciones formales de la sociedad. Es el lugar de encuentro diario de un pastor, unos visitantes y un grupo numeroso de internos; las demás personas que laboran en la institución, en funciones de tipo administrativo, médico y pedagógico, no tienen una presencia permanente $y$, hasta donde nos fue posible verificar, sólo existen en la presentación escrita de la institución.

Los días transcurren sin medios de información como podrían ser periódicos, radio, televisión o celulares, debido a que consideran que la "palabra de Dios" es suficiente para resolver "su problema". La terapia de rehabilitación consiste en orar, hacer artesanías y conversar.

Sobre este último aspecto - conversarse fundamenta el presente trabajo: la conversación entre los internos y la de estos con el personal especializado encargado. La interacción verbal, en una institución de este tipo, trasciende su carácter comunicativo hacia una intención terapéutica, en tanto permite realizar disertaciones y reflexiones acerca del consumo de sustancias psicoactivas y las dinámicas mismas de la vida alrededor de esta situación; sin embargo, esta intención terapéutica no se hace prioritaria en este Centro. 
En medio de las interacciones cotidianas, surge el relato de las historias de vida de los internos que pueden catalogarse como Narrativas conversacionales. Labov (1972:10) define la narrativa como "un método de recapitular experiencias pasadas apareando una secuencia de cláusulas verbales con una secuencia de eventos que, según se infiere, en realidad ocurrieron". Desde esta perspectiva, la producción verbal se da como respuesta a un estímulo específico, es decir, es inducida por el entrevistador. Tomando distancia de este modelo de producción, pero conservando su carácter teórico, la narrativa conversacional en la cotidianidad de la Casa Renacer, surge espontáneamente, en medio de la interacción comunicativa de los internos entre sí, situación que permite evaluar diferentes aspectos de su "sintaxis narrativa" y también de su forma de cohesión social, la cual supone la construcción de una parcela de intersección, en la que se llega a diversos consensos y en la que se comparten normas de uso del lenguaje, parcela a la que llamaremos Comunidad de habla Renacer.

El concepto de comunidad de habla (en inglés, speech community) es entendido por los estudiosos de la etnografía de la comunicación como un grupo social que comparte una misma variedad de lengua y unos patrones de uso de esa variedad. Francisco Moreno Fernández (1998), la define precisamente como "un conjunto de hablantes que comparten al menos una variedad lingüística, unas reglas de uso, una interpretación de ese uso, unas actitudes y una misma valoración de las formas lingüísticas”.

Dentro de las conversaciones aquí analizadas, se manifiestan los procesos de socialización de los muchachos que habitan en la
Casa Renacer, es decir, las reglas sociales y lingüísticas que rigen el comportamiento del grupo. En principio abordaremos, en este estudio, las motivaciones que llevan a los internos a permanecer en "La Casa", que a la vez se convierten en una de las temáticas recurrentes, en sus diálogos; posteriormente se considerará la estructura de las narrativas, haciendo énfasis en la evaluación, como elemento revelador de las reales intenciones pragmáticas de los participantes; finalmente describirán los mecanismos discursivos empleados por los muchachos, los cuales reflejan, de alguna manera, su orden social.

\section{Motivaciones de las narrativas}

La principal actividad realizada por los muchachoses la conversación y en ella abordan variados contenidos en sus intervenciones, sin embargo hay algunos temas que prefieren y que les permiten expresar sus pensamientos y sentimientos a manera de reflexión. Los internos de esta Casa, afirman que la sociedad no los acepta, que han sido rechazados y que no se les brinda oportunidad para trabajar y volver a ella, por eso han llegado a la institución con el fin de rehabilitarse. Así, en su testimonio, uno de ellos, sostiene:

Yo vuelvo, otra vez, al programa con la intención de recuperar nuevamente mis valores; -yo creo que yo valgo muchopero esta vez vengo con la intención de estar sinceramente frente a Dios, bien - pero quiero aprender algo-, quiero ..., aquí hay un ministerio que es sanidad interior, es la más importante para todos los muchachos que llegamos acá, en ella se orienta en qué partes de la personalidad estamos fallando. El problema mío no es de drogas y eso lo acaba de escuchar, y me parece muy real, porque yo lo siento en mi corazón, es la falta de aceptación en la sociedad. (Tomado de una de las narrativas del corpus).
El concepto de comunidad de habla (en inglés, speech community) es entendido por los estudiosos de la etnografía de la comunica ción como un grupo social que comparte una misma variedad delenguay unos patrones de uso de esa variedad. 
Ideas semejantes a éstas son las que forman parte del discurso que los muchachos internos emiten cuando están en presencia del pastor o de alguno de los líderes nombrados por él. No obstante, el resultado del trabajo de campo permite plantearse cuestiones relacionadas con la verdadera intención de los internos al acudir a la Casa Renacer. En principio, parece conllevar un objetivo explícito de rehabilitación; sin embargo, no todos los internos cumplen el programa a cabalidad y escapan de nuevo a sus antiguas andanzas. Esta situación reclama un análisis acerca de las verdaderas motivaciones de estas personas al acudir al centro de rehabilitación y cómo, si su visión se aleja del objetivo de la Casa, logran permanecer allí por espacios de tiempo prolongados.

Consideramos que estas cuestiones pueden ser resueltas, revisando la vida cotidiana del interno, quien pasa la mayor parte del tiempo envuelto en intercambios conversacionales. Mediante esta interacción verbal es posible determinar su comportamiento y detectar algunas reglas que han sido creadas en el seno de la comunidad. En apariencia, los internos reconocen la autoridad del pastor y de los líderes nombrados por él, pero realmente acatan únicamente las normas de aquellos que han negociado su liderazgo dentro de la comunidad misma.

Yo sinceramente, estoy aquí, estoy aquí, por la voluntad de Dios y más por la ayuda de Orienzo, el man, el man si es el que decide. Si uno quiere estar bien, respóndale a Orienzo y si quiere quedarse en el programa con la intención de recuperarse, respóndale al hombre y todo fluye; yo creo que yo puedo, pero necesito la ayuda de mis hermanos y de Orienzo. El jefe nos organiza, nos ayuda a resolver las peleas entre noso- tros, por la noche, por la mañana, cuando nadie está, ahí está el hombre, si entiende, ahí está. (Tomado de una de las narrativas observadas).

Orienzo, es un interno que goza de la aceptación del grupo que lo ha posicionado como líder, no ha sido elegido oficialmente por la autoridad administrativa de la Casa Renacer, pero síse le ha concedido el poder, porque goza de prestigio lingüístico en la Comunidad de habla Renacer.

Vale la pena citar el concepto de Prestigio en Sociolingüística, del profesor Moreno Fernández (1990:187), quien lo define como "un proceso de concesión de estima y respeto hacia los individuos o grupos que reúnen ciertas características y que lleva a la imitación de las conductas y creencias de esos individuos o de esos grupos", además agrega que puede ser considerado bien como una actitud, o como una conducta y que es algo que se tiene, pero que también se concede; situación reflejada en Orienzo.

\section{Estructura de la narrativa}

Siguiendo a Labov (1972:14), la narrativa se presenta como una estructura secuencial de cláusulas temporalmente ordenadas, cada una de las cuales se marca con letras minúsculas y cada intervención de un participante se identifica con números arábigos. Las convenciones usadas, llamadas también cláusulas u oraciones, pueden ser clasificadas según los siguientes componentes de la narrativa: sintesis, orientación, complicación, evaluación, resultado y coda.

La sintesis se presenta en algunas narrativas en las que el participante utiliza una o dos cláusulas para condensar el relato antes de empezar. Obsérvese la siguiente conversación: 
1. a) Yo desde chinche... como una enfermedad, a mí me trataron po' ahí diez sicólogos, porque la enfermedad mía era cogerme las cosas.

\section{2. a) Cleptomanía}

b) Pó ahí diez sicólogos, el último sicólogo dijo que no me volvieran a llevar porque me le robé to (todo): el juego de parqués.

c) Todo, ja ja ja

d) "Yo le decía: "Yo no soy loco, ese cuento de llevarme onde sicólogos".

e) Mi madrecita luchó mucho conmigo.

f) Vea, mi amá (mamá) hoy en día me dice: "John, vos tenés tantas historias".

g) Una vez llegó una visita... Y sirvió el almuerzo pa' toas (para todas).

h) Y era gallina, y créame que la maldad...

i) a to, a cada presa: "crunch, crunch, cras"

2. b) ¡Ay! no, no, no. Pero usted si era un chinche.

j) A toda las presas, les mordí los dientes, quedaron así (indica mordiéndose una mano).

k) Sí, uno es inquieto desde pequeño, yo no sé por qué es así siendo que uno nació en un hogar bien.

1) Mi mamá dice que: "nunca olvidará"

11) ...Que la señora iba a coger la presa, y...

m) cuando iba a morder,

n) ...y era el pedazo de mordisco...

n) a todos los seis platos, [les hice eso].

o) Ella dice: "de todo, lo que no olvidaré será eso"

La cláusula primera, sintetiza la información y es el preámbulo para lo que se ha de contar.
En la orientación, se contextualiza a los interlocutores, identificando el tiempo, el espacio, las personas y la situación, al igual que se hace en las cláusulas (g) y (h).

La acción complicante es la que aporta la información esencial de lo narrado, como en la cláusula (j).

La coda se define como una de la herramientas que tiene el narrador para indicar que la historia ha terminado, como en la cláusula (o).

Finalmente, la evaluación es descrita por Labov (1972:18) como "el medio empleado por el narrador para indicar la finalidad [objetivo] de la narrativa, su razón de ser", en otras palabras, las cláusulas u oraciones orientadas a lograr un efecto perlocutivo en el interlocutor que, generalmente buscan exaltar la visión del hablante como sujeto protagonista ante la persona que lo escucha. En las cláusulas (h) y (k) se ve la evaluación hecha por el interno, quien busca dejar constancia de su carácter fuerte y ajeno a las normas.

La evaluación se ubica a lo largo de la narrativa, en las diferentes cláusulas o en las intervenciones de los oyentes (que aquí no son interrupciones, ni robos de turno), en las cuales el narrador está usando su experiencia para enfatizar en su punto de vista. De alguna manera se puede hablar de una evaluación construida cooperativamente, como en la cláusula (2b), en la que uno de los interlocutores reafirma el protagonismo del interno que quiere sobresalir por su maldad. La adecuación del punto de vista depende de los contextos socioculturales, conversacionales y personales en los que se inserta la comunidad de habla (Schiffrin 1987:7). 


\section{Mecanismos discursivos}

Los muchachos tienen a su disposición una serie de mecanismos discursivos que les permiten interactuar y se convierten en recursos que posibilitan la expresión de su orden social. Tales mecanismos se evidencian con mayor claridad durante la terapia ocupacional en la cual los internos se organizan en grupos de trabajo y pasan horas dentro de un intercambio verbal. En su conversación incrustan historias de experiencias personales que responden a cuestiones acerca de cómo y por qué se da la narrativa en la conversación, y para qué o con qué intención un participante desarrolla su narrativa en este centro de rehabilitación.

Merece destacarse cómo la construcción de una historia, durante la conversación, se logra gracias a varios niveles del discurso que trabajan juntos para crearla. Schiffrin (1984:314) habla de la integración de una teoría del discurso en la cual "la sintaxis, la semántica y la pragmática del habla se contextualizan y el discurso es realizado por medio de las relaciones entre las estructuras, los significados y las acciones enmarcadas por sentidos sociales y culturales". Por una parte, lo narrado debe ser coherente con el contexto de situación y por otra, con el registro utilizado, en el cual queda claro que no hay significado sin uso y que las abstracciones sobre el significado de las palabras y de las expresiones conllevan implícitamente los valores que los hablantes aportan al mismo y que tanto sintaxis como pragmática están ligadas en este análisis.

Uno de los aspectos importantes para analizar será "la toma de turno", al respecto, Sacks, Schegloff y Jefferson publican en 1974 un artículo que se considera fundacional para el análisis conversacional, en él caracterizan la conversación como un sistema de toma de turno específico en la que sólo es

susceptible una cierta planificación parcial respecto a su propósito general, el cual incluso puede fracasar porque es frecuente que los hablantes intenten desarrollar ciertos temas pero luego no lo logran, en consecuencia, la conversación se va configurando sobre la marcha, turno-por-turno. Estos mismos autores muestran que la toma de turno tiene en cuenta la existencia de rasgos independientes del contexto y rasgos sensibles al contexto.

En el sistema de toma de turnos en la conversación no es fácil empezar una narrativa, como lo anota Schiffrin (1984:318), ya que el hablante que intenta introducirla debe lograr una suspensión del mecanismo normal mediante diversos recursos. Los internos, en su interacción verbal, cumplen con la proyección de un tema de interés mutuo, es decir, se abre una historia teniendo en cuenta la coherencia del tópico, es decir, entre el hecho a contar y la conversación precedente.

En este sentido, para Polanyi (1985:314), siempre hay algún tipo de conversación que hace el papel de entrada a la conversación propiamente dicha, generalmente incluye una especie de anuncio explícito o implícito de lo que trata la historia que se va a contar y algún tipo de aceptación, por parte de los destinatarios y de la intención del narrador. En la fase de entrada en el mundo de la historia del narrador (o provocador de la narrativa), se deja claro si se considera que la historia sea coherente con el tópico de la charla que lo precede.

Consecuente con lo anterior, antes de iniciar la narrativa,la siguiente oración: "A 
mí las mujeres me han salido re-malas", el informante JF completa la idea del participante anterior mediante un ejemplo que argumenta el tema de la conversación. Los interlocutores (internos de la Casa de rehabilitación) hablan sobre las diferencias entre un individuo como ellos y los hombres de la sociedad, plantean que son diferentes y que ellos carecen de un buen trato tanto en la familia como con los amigos. Se ayudan con una fonética expresiva en la repetición adverbial y adjetival que se va abriendo campo para dar paso a la historia.

M uno trae consigo de pronto como algo, algo que lo define a uno.

JF: Sí.

M: Diferente a los demás.

JF: Vea, yo he querido a las mujeres tanto, tanto, [pero] me han pagado tan mal las mujeres, ¡eh!, créamelo. Así las mujeres digan que uno es el malo, yo como que salí al revés, a mí las mujeres me han salido re-malas.

JF logra llamar la atención de los otros y a su vez garantiza para sí un periodo de discurso más largo e ininterrumpido, en el cual ubica su historia y compromete a los demás a atender lo que va a contar. Esto se efectúa mediante un alargamiento fonético y mediante el uso del par adyacente, los cuales crean un ambiente de suspenso.

Un par adyacente está formado por dos turnos conversacionales consecutivos y se caracteriza porque la presencia de la primera parte (el primer turno) hace que se espere a continuación una segunda parte determinada. Un ejemplo de esto es que a un turno del tipo /hola, qué tal?/ sigue uno como /Bien, ¿y tú?/. El par adyacente, pues, es la pareja mínima de la conversación.

JF: ¿No?, ¿quiere que le diga, quién me hizo esto? (Muestra una cicatriz). G: ¡Sí! (gestos)
JF: Una porcelana de mujer...

Cabe anotar que quienes logran con éxito abrir su historia en medio de la conversación son los líderes constituidos solidariamente, pues han negociado su rol y el derecho a ocupar un turno más largo.

Otros líderes, en lugar de utilizar el mecanismo de pregunta-respuesta como en el anterior caso, utilizan un abstract o síntesis pero acompañado de un tono fuerte que atrae la atención, al igual que diminutivos, comparativos o superlativos como en las conversaciones que hemos titulado: "mi madrecita luchó mucho conmigo" o "tan caspa" donde, además de abrir espacio para su narrativa, hacen desde ya una evaluación de lo que se narra. En algunas ocasiones establecen una especie de duelo verbal cuyo fin es determinar quién es "el más cruel", "el más caspa" o "el duro" de la calle y "el duro" aquí en el grupo.

La finalidad de las historias contadas por los líderes de la Casa Renacer es la de establecer y convencer de su autoridad y superioridad, lo cual lleva a afirmar que el lenguaje en la narrativa es usado como instrumento de poder y dominio. (Ya arriba se mencionó el concepto de prestigio lingüístico)

Vea niña, nosotros aquí, niña trabajamos en la alcancía, si, la terapia, todos, que un pedazo de pan, que una agüepanela, que un banano, pa' todos. Pero como yo le decía Orienzo, o John, ellos disponen, si ve... bueno así es...

La comunicación entre los miembros de la comunidad se lleva a cabo en el marco de unos eventos comunicativos que estructuran y desarrollan la vida social del grupo. Aquí se ve cómo el grupo ha elegido líderes y cómo siguen las leyes que han negociado, así como también el momento de las con-
La finalidad de las historias contadas por los líderes de la Casa Renacer es la de establecer y convencer de suautoridady superioridad, lo cual lleva a afirmarque el lenguaje en la narrativa es usado como instrumento depodery dominio. 
versaciones, el compartir sus alimentos, pues cuando conversan y conversan, legitiman su existencia como grupo, unos oyen, otros cuentan, otros ríen y asienten, todos son cómplices de las historias que reviven sus experiencias pasadas.

Más aún, los líderes buscan convencer que, así como viven en la calle, viven bien y no quieren cambiar. Dicha finalidad se lleva a término, mediada por la puesta en escena de la narrativa, en virtud de unos marcadores discursivos que son el discurso reproducido y la risa, elementos que dramatizan la historia y así se convierten en un ejemplo que sustenta el tema de conversación que se está desarrollando.

Según Concepción Maldonado (1991), el narrador se vale del discurso emitido, entendido como la reproducción de un enunciado verbal, con el afán de presentar al oyente una historia actuada que convenza, no sólo del acto lingüístico, sino de la situación total del enunciación. Al respecto, la autora analiza dos tipos de discurso reproducido: el directo y el indirecto.

Todo discurso directo (DD) está constituido por una expresión introductora (El) que contiene un verbo de decir flexionado, una cita directa $(C D)$ marcada tipográficamente por guiones o comillas, y el contenido citado (CC), siempre reproducción literal de un enunciado. La EI y la CD están separadas por una pausa marcada tipográficamente por los dos puntos. Todo discurso indirecto está constituido por una expresión introductora (El) que contiene un verbo de decir flexionado, una cita indirecta (CI) cuya marca es la conjunción que, y el contenido citado (CC). La CI está subordinada al verbo de la EI. (Maldonado 1991: 30).

En el análisis de esta estructura se ve cómo las intervenciones crean significado y se usan para realizar una acción.
Uno de los puntos del análisis del manejo del discurso reproducido en las narrativas de los internos de la Casa Renacer es la elisión de los verbum dicendi o declarativos (afirmar, admitir, asegurar, etc), aspecto que nos llevaría a negar su carácter, según las definiciones citadas anteriormente. No obstante, los narradores, ejerciendo su pleno papel de actores, estratégicamente hacen cambios de registros con un manejo adecuado de la voz acompañada de kinesis y proxemia que permiten ubicar e identificar el personaje cuyo discurso ha sido reproducido.

En otros casos no es característica la elisión sino, al contrario, la presencia del verbum dicendi la que muestra un juego entre el uno y el otro.

ELLOS SABEN CÓMO ES EL VICIO

a) En una oportunidad pues se reunieron, me acuerdo.

b) El agente Amado dice: "No pues a Orienzo, a 'sopla sopla' hay que ponerlo ya a trabajar"

c) ...y me compraron un bulto de limones.

d) Me puse a venderlo al lado del CAI...

e) ...entonces como allá en el mercado, pues todos rodean el CAI...

f) ...entoes (entonces) a todos los limoneros, los policías: "ábranse de aquí"

g) ...y yo quedé pues con la plaza.

Aquí se ve el manejo del discurso reproducido con o sin el verbum dicendi; sin embargo, en ambos se puede captar la reproducción de la situación. Por ejemplo, el narrador, Orienzo, explica cómo es protegido por Amado, el policía del CAI, y reproduciendo el discurso en las cláusulas (b) y (f) nos ubica en la situación del mercado, del puesto donde Orienzo vendería los limones de otros vendedores que suponemos están ahí y que son desplazados para que finalmente Orienzo, quede con la plaza. 
Toda esta construcción del contexto se logra gracias al discurso reproducido.

o) ...y cuando ya se acabó la plata...

p) ...y ahora !uy! ¿con qué alientos voy donde Sonia?...

q) ...entoes (entonces) me la inventé, hice una llamada: “¿Amado?, Sí, a la orden”... r) ...entoes imposté la voz: No, es que aquí del agente Martínez, de la estación Cien, ¿usté conoce a un joven llamado Orienzo Arenas, que fue anoche apresado, en una batida y se encuentra acá? [...] y que tal... s) ...dijo: "Sî"

t) ...y dije: "no lo que pasa es que lo mandé para allá"

u) ...yo pagué un taxi, haciéndome quedar mal y to (todo)"...

v) ...y llegué con el costal de los limones...

w) ....¿y no saben qué?, que me dejó una noche y allá en el calabozo me bajaron lo de las ganancias.

Ustéasí (gestos)

En esta narrativa, el informante ' $O$ ', habla con sus compañeros de cómo es el vicio y de cómo el drogadicto no logra separarse de él; paradójicamente, contrario a lo que ellos afirman, 'O' deja ver en su discurso que efectivamente la sociedad le ha brindado medios de rehabilitación pero que él no los ha aceptado.

Además, el ser protagonista de esta situación -y burlar al otro en un juego verbal de alusión al otro y nuevamente a sí mismo, mezclando negaciones y afirmaciones-, devela un manejo del lenguaje, propio de un líder, con miras a sobresalir y demostrar a los demás su dominio de la situación. En ese momento, se nota un uso reiterativo del pronombre de la primera persona: YO.

Toda esta narrativa incrustada en la conversación y dramatizada, se convierte en un ritual. Marc y Picard (1992), con base en los trabajos de Goffman (1974), señalan que el significado de los rituales no se percibe enteramente. Si no se tiene en cuenta 'lo que se juega' en la interacción.

Cada actor busca en el encuentro, dar una imagen valorizada de sí mismo; va a intentar organizar una puesta en escena del "Yo" (moi) que tenga en este sentido. No obstante, esta imagen pide ser reconocida y confirmada por sus compañeros. (Goffman, 1974).

En la interacción de la comunidad de habla de la Casa Renacer, se busca dar una imagen de sí mismo, en donde los rasgos son atributos aprobados socialmente. Cuidar o salvaguardar la imagen del líder es lo que se juega en esta interacción social.

En este ejemplo, se puede observar lo siguiente:

g) ...y yo quedé pues con la plaza...

h) ...y yo, venda limón...

l) ...me los metí...

11) ...se los metió todos, ja...

Los intercambios lingüísticos, según Bourdieu (2002), son también relaciones de poder simbólico donde el destinatario y su interlocutor actualizan relaciones de poder. La circulación lingüística se establece en una relación de intercambio dentro de un mercado en el cual se ofrece el producto bajo unas condiciones sociales concretas. Así en este caso, el ser el más fuerte y al mismo tiempo el más astuto y hasta malvado en palabras de ellos "el duro", "el caspa” es la actitud que está en juego para instituirse como líder en el grupo, pues de alguna manera es un contrapunteo de narrativas, el criterio que ha de definir, quién es el líder, el Yo puesto en 
escena que permite vender esa imagen en este "mercado lingüístico".

También cabe rescatar en este ejemplo, la evaluación lograda por el comentario final en la cláusula (ll), que se convierte en el reconocimiento de su hazaña. En la acción que se complica: "A mí las mujeres me han salido re-malas", también se

El narrador cuenta esta historia como un chiste en donde podemos ubicar una función subversiva del lenguaje de la que habla Juan Gómez (1981) quien plantea que una de las características del chiste es la oposición alorden establecido. El chiste se opone a la cultura oficial, al tono serio, religioso, autoritario. aprecia el uso del discurso reproducido y la elisión de los verbum dicendi.

\section{A MÍ LAS MUJERES ME HAN}

\section{SALIDO RE-MALAS}

c)...Y sabe qué; borracho...

d) ...se fue con la mejor llave...

e) ...borracho,

f) ...de confianza: "mi amor, tómese un chorrito"

g) ... y yo: “'Ay! sí mamita, pase”...

h) ....cuando me lo estaba tomando, llegó y "taaj"...

i) ...así, un solo, con una pate-cabra.

La ausencia del verbo decir se suple con una cláusula evaluativa que se reitera e intensifica con la entonación. La expresión 'de confianza' cumple la función de verbum dicendi y adicionalmente pone en evidencia el hecho de que alguien traicionó al líder, pero que después tuvo que enfrentarse a su venganza. En la cláusula "cuando me lo estaba tomando, llegó y ¡taaj!”, la onomatopeya además de intensificar la acción que se complica, le da el carácter dramático evaluador a la historia, el líder estuvo en una situación de peligro, pero finalmente se salvó.

En las narrativas tituladas: "Se habían rascado con los cepillos", en "Tan caspa” y en "Ellos saben cómo es el vicio" aparece otro mecanismo relevante en la dramatización de la narrativa: la risa. Este marcador se convierte en un elemento de contacto entre los participantes y los lleva a compartir la experiencia pasada.
Obsérvese el siguiente ejemplo:

\section{SE HABÍAN RASCADO CON LOS CEPILLOS}

j) ...En una fiesta, en la fiesta de mi primera comunión, ¡una fiesta de primera comunión! ...

k) ...poníamos a tres cepillos encima de la cisterna para que se rascaran, ja ja ja ...

1) ...y ¿ssabes qué? ellos iban saliendo ...

11) ...o sea, pareja, señora que le diera por ganas de ir a hacer pipi...

m.) ...chichi

n) ...eso e a hacer chichi, entoes, ja ja ja...

En esta narrativa, en cada una de sus cláusulas desde la síntesis hasta la coda, el narrador mantiene un tono de burla y ríe evaluando la situación.

Esa risa con tono irónico expresa la situación del hablante frente a los demás, situación en la que se burla de una reunión establecida por el orden social y religioso, al que podríamos inferir que él se opone, pues se hace un énfasis mediante el mecanismo de la repetición (en una fiesta, en la fiesta de mi primera comunión, una fiesta de primera comunión...) de la forma como él se burló del encuentro.

El narrador cuenta esta historia como un chiste en donde podemos ubicar una función subversiva del lenguaje de la que habla Juan Gómez (1981) quien plantea que una de las características del chiste es la oposición al orden establecido. El chiste se opone a la cultura oficial, al tono serio, religioso, autoritario.

Esta oposición es el resultado de la acción de aquellas fuerzas centrífugas que en el terreno lingüístico tienden a la descentralización y desunión ideológica' por oposición a las fuerzas centrípetas que tienen a la unificación y centralización del mundo ideológico (Gómez, 1981:41). 
Se había mencionado que uno de los fines de la narrativa de los líderes es la función de convencer al interlocutor, el cual no desea cambiar su modo de vida, sino que prefiere continuar como está, esta es la razón por la que se burla de la sociedad.

Otra narrativa que expresa esta evaluación es “Tan caspa”, en donde el hablante M' no debería reír al contarla, sino al contrario, mostrar arrepentimiento de los hechos pasados en la vida de la calle. Sin embargo, él irónicamente ríe y se vanagloria de su audacia en el atraco "a un man, ja ja, a un tipo", y muestra orgullo por ser "Tan caspa".

La finalidad de la narrativa conversacional, en un momento, no es sólo la del líder, sino la del grupo en general, muestra de ello es la siguiente conversación:

\section{ELLOS SABEN CÓMO ES EL VICIO \\ g) ...y yo quedé pues con la plaza... \\ h) ...y yo venda limón... \\ i) ...me hice cuarenta y cincuemil de pesos... \\ j) ...ese sí me pelé... \\ k) ...y me jui (fui), ja ja je... \\ l) ...me los metí \\ 11) ...ise los metió todos?, ja, ja, ja...}

Es paradójico que el protagonista 'O' se esté riendo de su recaída, después de tener una oportunidad de empleo, pero lo más interesante y que evalúa irónicamente lo contado, es la risa grupal, en donde hay un juego participativo en donde todos actúan riendo. Aquí cualquiera se confundiría frente a lo observado pues el escenario es una casa de rehabilitación cristiana y parece que la interacción es más bien una de las reuniones del ruedo' en donde "los muchachos" disfrutan contando sus experiencias pasadas y reafirman su carácter delincuencial.
Otro aspecto relevante en la interacción de la Casa Renacer es la construcción cooperativa de la narrativa conversacional, la cual surge en la interacción comunitaria, al parecer como un consenso de participación que permite la cohesión del grupo. Hacemos referencia al Principio cooperativo de Grice, el cual es un modelo pragmático que, sin ser prescriptivo, sugiere lo siguiente: "haga que su contribución a la conversación sea, en cada momento, la requerida por el propósito del intercambio comunicativo en el que usted está involucrado". Este es un principio que se supone aceptado tácitamente por todos los que participan en la conversación y que se desglosa en máximas de cantidad, de calidad, de relación y de modo. Se puede hacer alusión a cualquiera de las máximas del principio de Grice para evidenciar cómo en el cumplimiento o en la violación de las mismas, surge el reconocimiento del grupo y su cohesión.

En cuanto a la de cantidad (haga su contribución tan informativa como se requiera), se muestra cómo cada participante ha negociado su derecho al turno y a la duración de su intervención. Son "los duros" los que por un lado han ganado su derecho a contar su narrativa y "el más caspa" el que lleva el liderazgo, no sólo de la conversación, sino del grupo.

En lo concerniente a la máxima de calidad (intente que su contribución sea verdadera), el uso del deíctico: YO, y la narración en primera persona se convierten en un recurso para argumentar sobre la veracidad de los hechos.

En la máxima de modo (sea claro, ordenado, breve y evite la ambigüedad y la oscuridad), el líder cuenta la historia pero 
en algunos momentos se vale de una vacilación, de un alargamiento vocálico o consonántico de una repetición, de una pregunta o de un silencio para que alguien complete o apoye su idea e incluso para que evalúe su historia. La historia se construye entre todos porque saben cómo hacerlo en grupo.

Finalmente, en la máxima de relación (que su contribución sea relevante), se observa la forma como se propone una temática y se mantiene la coherencia.

\section{La conversación como terapia}

La biología de la cognición planteada por Maturana (1992), considera que los seres humanos somos seres en el lenguaje. Solo existimos como tales en el "lenguajear", y desde esta perspectiva, ser humano consiste en ser parte de una red de conversaciones o manera de fluir juntos en el lenguaje. Maturana plantea diversos tipos de conversaciones: a) de acusación, b) de aceptación, c) de rechazo; y las del deber ser en las cuales nos señalamos a nosotros mismos la culpabilidad en el cumplimiento o incumplimiento de un valor o norma cultural. Para Maturana la psicoterapia es una red particular de conversación, en donde se entrelazan: lenguaje y emoción, según el tipo de conversación que sustenten terapeuta y paciente, en donde la tarea del primero es guiar el curso de las conversaciones, pues es así como se desarrolla una relación paciente-terapeuta totalmente implicados, relación que es la base del éxito de la terapia.

La terapia inicia porque se parte de la presunción de que el discurso del paciente manifiesta una ceguera cognitiva y afectiva, provenientes, probablemente, de sus mecanismos de autoengaño que lo llevan a dar explicaciones acomodadas a ciertas situaciones o eventos negativos que han facilitado el consumo, pese a sus aparentes propósitos de rehabilitación. Esa contradicción debe ser evidenciada por el terapeuta para completar un proceso liberador y debe ser reconocida por el paciente; los muchachos de la Casa Renacer no son orientados en esa anomalía explicitada en el discurso y no alcanzan a facilitar el proceso de confrontación y a reformular una coherencia operacional que los lleve a un consenso de lo que desean lograr y de los medios para conseguirlo.

En las narrativas observadas en La Casa Renacer, se puede ver que no hay un especialista terapeuta que pueda orientar las conversaciones y entonces es el colectivo solo se convierte en interlocutor terapeuta, lo que genera unas condiciones diferentes para el proceso de rehabilitación, en este caso no se evidencia que haya rehabilitación a partir dela conversación, sino más bien que las narrativas tienen propósitos de cohesión y liderazgo.

\section{A manera de conclusión}

La narrativa conversacional en la Casa Renacer exige la participación tanto del emisor como del destinatario, razón por la cual el presente análisis evidenció una construcción cooperativa del discurso debido a los intereses propios de la comunidad. Por ello, se entiende cómo ese principio se convierte en un supuesto pragmático del intercambio comunicativo, por el que se espera un determinado comportamiento entre los interlocutores como consecuencia de un acuerdo previo de colaboración en la tarea de comunicarse, y como guía de los participantes.

Los muchachos internos de la Casa Renacer, tienen en la narrativa conversacional, un instrumento que permite la ins- 
tauración y el mantenimiento de un orden social en su comunidad, la cual viene a ser un grupo de individuos, dirigidos por unos líderes que negociaron su estatus y poder, y de esa manera lograron el "prestigio" y la aceptación, convirtiéndose, al mismo tiempo, en el foco de atención y en unos agentes propiciadores de la cohesión del grupo.

La construcción de la historia se da en la conversación, a manera de ejemplo que sustenta el tópico de la conversación, y, a la vez, reafirma la cohesión del grupo y los roles sociales dentro de éste. El narrador hace uso de la dramatización narrativa para asegurar el cumplimiento de su finalidad.

En las narrativas conversacionales desarrolladas por la comunidad de habla en la Casa Renacer, se hace énfasis en la risa y el discurso reproducido con una función social que establece las relaciones entre los internos, ya que este elemento narrativo cumple una función expresiva en la cual se manifiestan sus sentimientos.

Los internos de la Casa Renacer permanecen en ella por el tiempo que quieran. Sin embargo, no permanecen con el propósito de rehabilitarse, sino que hacen uso de ella como un albergue en donde se suplen sus necesidades básicas mientras se recuperan momentáneamente de la droga. En cuanto se sienten bien, vuelven a la calle, lo cual demuestra que los muchachos que llegan como internos a la Casa Renacer, no quieren cambiar su forma de vida.

Lo anterior demuestra que la Casa Renacer no es un ministerio de rehabilitación, sino un lugar de paso, esto se concluye a partir de las temáticas de sus narrativas en las que no se juega quien es el más bueno, el más arrepentido, el más cercano a la rehabilitación, sino quién es el más “duro", es decir, el más fuerte, el más listo y el que es capaz de sortear las situaciones con actuaciones que, sin importar la trasgresión de normas, le permitan ser el ganador.

No hay énfasis en actividades de tipo terapéutico a través de la conversación entre un profesional y los internos, ni siquiera hay un terapeuta; por tanto, las narrativas refuerzan las conductas que tenían antes de su llegada a la Casa Renacer, y los fortalece para nuevamente salir al medio del cual provienen con los mismos comportamientos. En la indagación etnográfica de la comunidad en la Casa Renacer, no se registra un sólo muchacho que se haya rehabilitado o reinsertado.

Finalmente, las narrativas objeto este análisis, demuestran que ellas no cumplen una función terapéutica, sino, más bien, que se usan para reafirmar el liderazgo y la cohesión dentro del grupo, mientras conviven temporalmente en la Casa Renacer.

\section{Bibliografía}

1. Bourdieu. (2002). El mercado lingüístico. En: Sociología y cultura (pp. 143-158). México: Grijalbo, Conaculta.

2. Gómez, J. M. (1981). El chiste: una aproximación sociolingüística. En: Forma y Función, (1). Universidad Nacional.

3. Goffman, E. (1961). Internados. Ensayos sobre la situación social de los enfermos mentales. Buenos Aires: Amorrortu.

4. Grice, P. (1983). La lógica y la conversación. En: Lenguaje y Sociedad. Centro de Traducciones. Cali: Universidad del Valle. pp. 101-121. 
5. Labov, W. (1972). "La transformación de la experiencia en sintaxis narrativa". En: Cuadernos de traducción (1). Cali: Universidad del Valle, Centro de traducciones (Traducción de Martha Bartrina de Cobo).

6. Maldonado, C. (1991). Discurso directo y discurso indirecto. Madrid: Taurus Universitaria.

7. Maturana, H. (1992). Emociones y Lenguaje en Educación y Política. Santiago de Chile: Universitaria.

8. Marc E. y Picard D. (1992). La interacción social. Cultura, instituciones y comunicación. Barcelona: Paidos.

9. Moreno Fernández Francisco(1998). Principios de Sociolinguistica y Sociología del Lenguaje. Barcelona: Ariel

10.Polanyi, L. (1985). “Conversational Storytelling”. En: Van Dijk, T. A. (Ed.). (1985). Handbook of discourse analysis. v. 3. London Orlando: Academic Press.

11.Sacks, H.; Schegloff, E. y Jefferson, G. (1974). "A symplest systematics for the organization of turn-taking for conversation”, Language, 50.4 (696-735)

12. Schiffrin, D. (1984). "How a history says what it means and does". En: Text No.4 13. . (1987). Discourse markers. Cambridge: University Press. 